Louisiana State University

LSU Digital Commons

$10-24-2005$

\title{
Immunocytochemical localization of small-conductance, calcium- dependent potassium channels in astrocytes of the rat supraoptic nucleus
}

\author{
William E. Armstrong \\ University of Tennessee Health Science Center \\ Adam Rubrum \\ University of Tennessee Health Science Center \\ Ryoichi Teruyama \\ University of Tennessee Health Science Center \\ Chris T. Bond \\ Oregon Health \& Science University \\ John P. Adelman \\ Oregon Health \& Science University
}

Follow this and additional works at: https://digitalcommons.Isu.edu/biosci_pubs

\section{Recommended Citation}

Armstrong, W., Rubrum, A., Teruyama, R., Bond, C., \& Adelman, J. (2005). Immunocytochemical localization of small-conductance, calcium-dependent potassium channels in astrocytes of the rat supraoptic nucleus. Journal of Comparative Neurology, 491 (3), 175-185. https://doi.org/10.1002/ cne.20679

This Article is brought to you for free and open access by the Department of Biological Sciences at LSU Digital Commons. It has been accepted for inclusion in Faculty Publications by an authorized administrator of LSU Digital Commons. For more information, please contact ir@lsu.edu. 


\title{
Immunocytochemical Localization of Small-Conductance, Calcium-Dependent Potassium Channels in Astrocytes of the Rat Supraoptic Nucleus
}

\author{
WILLIAM E. ARMSTRONG, ${ }^{1 *}$ ADAM RUBRUM,${ }^{1}$ RYOICHI TERUYAMA, ${ }^{1}$ \\ CHRIS T. BOND, ${ }^{2}$ AND JOHN P. ADELMAN ${ }^{2}$ \\ ${ }^{1}$ Department of Anatomy and Neurobiology, University of Tennessee Medical School, \\ Memphis, Tennessee 38163 \\ ${ }^{2}$ Department of Behavioral Neuroscience, Vollum Institute, Oregon Health and Science \\ University, Portland, Oregon 97239-3098
}

\begin{abstract}
Supraoptic nucleus (SON) neurons possess a prominent afterhyperpolarization (AHP) that contributes to spike patterning. This AHP is probably underlain by a small-conductance, $\mathrm{CA}^{2+}$-dependent, $\mathrm{K}^{+}$type 3 (SK3) channel. To determine the distribution of SK3 channels within the SON, we used immunocytochemistry in rats and in transgenic mice with a regulatory cassette on the SK3 gene, allowing regulated expression with dietary doxycycline (DOX). In rats and wild-type mice, SK3 immunostaining revealed an intense lacy network surrounding SON neurons, with weak staining in neuronal somata and dendrites. In untreated, conditional SK3 knockout mice, SK3 was overexpressed, but the pericellular pattern in the SON was similar to that of rats. DOX-treated transgenic mice exhibited no SK3 staining in the SON. Double staining for oxytocin or vasopressin neurons revealed weak co-localization with SK3 but strong staining surrounding each neuron type. Electron microscopy showed that SK3-like immunoreactivity was intense between neuronal somata and dendrites, in apparent glial processes, but weak in neurons. This was confirmed by using confocal microscopy and double staining for glial fibrillary acidic protein (GFAP) and SK3: many GFAP-positive processes in the SON, and in the ventral dendritic/glial lamina, were shown to contain SK3-like immunoreactivity. These studies suggest a prominent role of SK3 channels in astrocytes. Given the marked plasticity in glial/neuronal relationships, as well as studies suggesting that astrocytes in the central nervous system can generate prominent $\mathrm{CA}^{2+}$ transients to various stimuli, a $\mathrm{CA}^{2+}$-dependent $\mathrm{K}^{+}$channel may help $\mathrm{SON}$ astrocytes with $\mathrm{K}^{+}$buffering whenever astrocyte intracellular $\mathrm{CA}^{2+}$ is increased. J. Comp. Neurol. 491: 175-185, 2005. ๑ 2005 Wiley-Liss, Inc.
\end{abstract}

Indexing terms: vasopressin; oxytocin; glial fibrillary acidic protein; SK3; afterhyperpolarization

\begin{abstract}
Neurosecretory neurons in the hypothalamic supraoptic nucleus (SON) synthesize and release the hormones oxytocin (OT) and arginine vasopressin (AVP) from terminals in the neural lobe of the pituitary gland. Deficits in blood volume, pressure, or extracellular fluid tonicity trigger release of both hormones, with AVP having a primary role in the elevation of pressure via vascular receptors and the conservation of water with antidiuretic actions in the kidney (Sladek, 2000) and OT acting primarily as a natriuretic in these circumstances (Verbalis et al., 1991). During labor and lactation, OT is selectively released to promote uterine and mammary myoepithelial cell contractions, respectively (Crowley and Armstrong, 1992).
\end{abstract}

Release of both hormones to these stimuli is governed by the rate and pattern of action potential activity in OT and AVP neurons (Poulain and Wakerley, 1982). A prominent

Grant sponsor: National Institutes of Health; Grant number: NS-23941; Grant number: HD-41002 (to W.E.A.); Grant number: NS-38880 (to J.P.A.).

*Correspondence to: William E. Armstrong, Department of Anatomy and Neurobiology, University of Tennessee Medical School, 855 Monroe Avenue, Memphis, TN 38163. E-mail: warmstrong@utmem.edu

Received 25 February 2005; Revised 25 April 2005; Accepted 12 May 2005 DOI 10.1002/cne.20679

Published online in Wiley InterScience (www.interscience.wiley.com). 
property of SON neurons controlling spike frequency is an apamin-sensitive, $\mathrm{CA}^{2+}$-dependent afterhyperpolarization (AHP; Bourque and Brown, 1987) that is characteristic of both cell types (Armstrong et al., 1994). It is kinetically of medium duration $(100-500 \mathrm{~ms})$ relative to the fast AHP that follows single spikes and the slow AHP expressed after long, or high-frequency, spike trains (Greffrath et al., 1998; Ghamardi-Langroudi and Bourque, 2004). Considering its apamin sensitivity as shown by in situ hybridization (Stocker and Pedarzani, 2000; Toccani et al., 2001) and immunochemical (Greffrath et al., 2004) studies, the medium AHP (mAHP) is most likely associated with SK3 channels (Bond et al., 2004; Villalobos et al., 2004).

Our own interest in the mAHP (Armstrong et al., 1994; Teruyama and Armstrong, 2002; Roper et al., 2003) led us to investigate SK3 immunoreactivity within the SON, in terms of both verifying SK3 protein in both cell types and determining somatodendritic distribution. We found to our surprise that SK3 immunoreactivity was more intensely displayed around, rather than within, neurons or their processes. This perineuronal SK3 reactivity is largely associated with astrocytes. Data from this study have previously appeared in abstract form (Armstrong et al., 2003).

\section{MATERIALS AND METHODS Animals}

Adult, female virgin Sprague-Dawley rats (random cycling; 150-250 g) were purchased from Charles River (Wilmington, MA). Wild type (W-T) C57BI/6 mice and $\mathrm{C} 57 \mathrm{BI} / 6$ mice with a regulatory cassette in the SK3 gene $\left(\mathrm{SK}^{\mathrm{T} / \mathrm{T}}\right)$ were provided by the Vollum Institute, Oregon Health Sciences University (see Bond et al., 2000, for details). The switch to abolish SK3 gene expression was activated with dietary doxycylcine (DOX) for at least 5 days. Untreated animals typically show overexpression of protein (Bond et al., 2000; Taylor et al., 2003).

\section{Immunocytochemistry}

For light microscopy, animals were anesthetized deeply with sodium pentobarbital $(60 \mathrm{mg} / \mathrm{kg})$ and perfused transcardially with $0.01 \mathrm{M} N a$ phosphate-buffered saline (PBS; $\mathrm{pH}$ 7.2-7.4), followed by a fixative of $4 \%$ paraformaldehyde/ $0.1 \%$ picric acid in $0.15 \mathrm{M}$ sodium phosphate buffer $(\mathrm{pH}$ 7.2-7.4). The brains were extracted and postfixed in the same fixative for 1-3 days. Typically, 75- $\mu \mathrm{m}$ sections were cut on a vibrating microtome (Lancer, St. Louis, MO), but some brains were infiltrated with sucrose (30\%) and sectioned at $40 \mu \mathrm{m}$ on a freezing microtome. In either case, sections were rinsed in PBS and incubated in primary antibodies overnight at $4^{\circ} \mathrm{C}$. A polyclonal antibody was used for SK3 localization (Alomone, Jerusalem, Israel). The SK3 antibody was raised in rabbit against amino acid residues 2-21 (DTSGH FHDSG VGDLD EDPKC) of human SK3, which represents an N-terminal, intracellular domain that is identical to that in rat SK3. Absorption controls for SK3 were run with $1 \mu \mathrm{g}$ peptide/ $\mu \mathrm{g}$ antibody. Specific staining was observed with $1: 500$ to $1: 2,000$ dilutions.

Monoclonal antibodies were used to detect glial fibrillary acidic protein (GFAP; G-A-5, Sigma, St. Louis, MO) or OT- (PS36) or VP-associated neurophysins (PS41; provided by $\mathrm{H}$. Gainer, NIH), allowing double staining with SK3. Although specific neurophysins are not available for absorption tests, the OT- and VP-neurophysin antibodies have been well characterized (Ben-Barak et al., 1985). Similarly, the G-A-5 monoclonal antibody is specific for GFAP relative to other intermediate filament proteins expressed in some astrocytes, such as vimentin (Debus et al., 1983; Franke et al., 1991). Reaction product for single staining of SK3 was achieved with goat anti-rabbit biotinylated secondary antibody (1:200) followed by the standard ABC-diaminobenzidine procedure per the protocol provided by Vector (Burlingame, CA). Incubation time for $\mathrm{ABC}$ ranged from 4 hours to overnight. Sections were mounted on gelatin-coated slides, dehydrated, and coverslipped with Permount. Light microscopic images were acquired digitally with software from IP Labs (Scanalytics, Fairfax, VA) and a Photometrics (Tucson, AZ) cooled CCD camera (SenSys). Digital images $(1,317 \times 1,035)$ were minimally altered in Adobe Photoshop (Adobe Systems, San Jose, CA) with small changes in dynamic range.

For double labeling, SK3 antiserum was combined with monoclonal antibodies for PS36, PS41, or GFAP in cocktails. Dilutions were as follows: anti-SK3, 1:500; antiGFAP, 1:5,000; PS36, 1:500; PS41, 1:5,000. For detection, goat or horse anti-mouse fluorescent-conjugated secondary antisera (fluorescein isothiocyanate [FITC] or Texas Red fluorophores; from Jackson ImmunoResearch, West Grove, PA, Vector, or Sigma) were used at 1:200, also in cocktails. All antibodies were diluted with PBS containing $0.5 \%$ Triton $\mathrm{X}-100$. Incubation times for primary and secondary antibody cocktails were overnight at $4^{\circ} \mathrm{C}$. Sections were rinsed in PBS and mounted on glass slides with 50\%:50\% glycerol/PBS. Coverslips were sealed with nail polish. Tissue sections were examined with a confocal microscope (1024, Bio-Rad, Hercules, CA) equipped with a krypton-argon laser. FITC was examined with a 488-nm excitation filter (emission bandpass $522 \mathrm{~nm}$ ), and Texas Red was examined with a 568-nm excitation filter (emission bandpass $605 \mathrm{~nm}$ ). The optical section thickness was $1 \mu \mathrm{m}$. These were viewed singly, or in stacks of 5-20 sections by using 40,60 , or $100 \times$ oil immersion objectives (n.a. $=1.35,1.4$, and 1.4, respectively). Confocal images (either $512 \times 512$ or $1,024 \times 1,024$ ) were acquired as 24-bit color images and viewed by using ImageJ (NIH) software. Merged images of $1-\mu \mathrm{m}$ sections were made in ImageJ from raw confocal images. Confocal figures were made in Adobe Photoshop, with minimal alteration in dynamic range.

\section{Electron microscopy}

A standard $\mathrm{ABC}$ immunoperoxidase localization was used, except that primary antibody solutions did not contain Triton-X. The fixative above contained an additional $0.25 \%$ glutaraldehyde, and sections were pretreated with $0.5 \% \mathrm{H}_{2} \mathrm{O}_{2}, 1 \%$ sodium borohydride to reduce background staining. Penetration of antibodies on the Vibratome section without detergent was limited to less than $5 \mu \mathrm{m}$. Following the diaminobenzidine (DAB) reaction, sections were reacted with $1 \%$ osmium in PBS for 1 hour. Osmicated sections were dehydrated, stained en bloc with $2 \%$ uranyl acetate, and embedded in plastic (Spurr's resin, EMS, Fort Washington, PA). Ultrathin (75-80 nm) sections were contrasted with lead citrate and uranyl acetate and viewed at $60-100 \mathrm{kV}$ on a JEOL $2000 \times$ transmission electron microscope. Images were acquired either on film or with a digital camera. Negatives were scanned at 2,000 dpi and down-sampled to 1,000 dpi with Adobe Photoshop, by which small changes were made in dynamic range. 


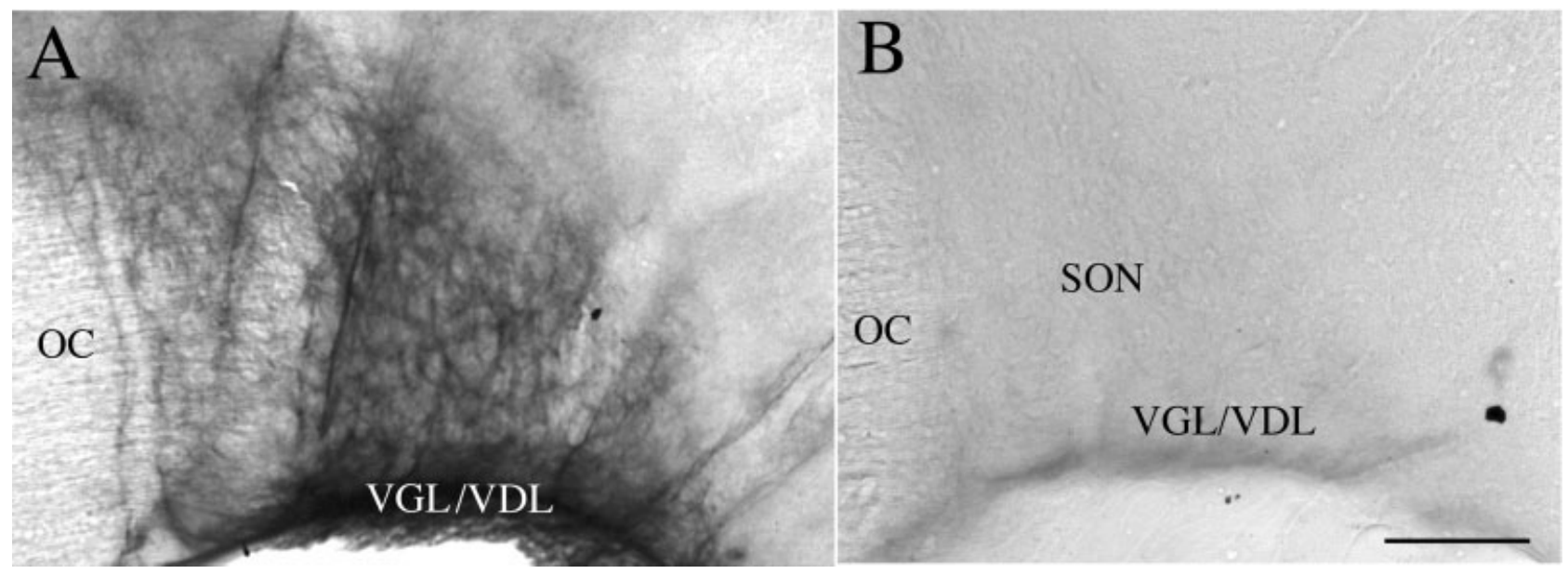

Fig. 1. Immunochemical localization of SK3-like protein in rat supraoptic nucleus (SON) from $75-\mu \mathrm{m}$ coronal sections taken on a Vibratome. A: Staining in the SON using the ABC method with an antibody dilution of $1: 1,000$. Note the lacy appearance of the staining: cells are outlined with dark staining. Staining is very dense in the ventral glia and dendritic lamina (VGL/VDL). B: Absorption control in another section from the same brain using the same antibody dilution. Immunoreactivity was abolished when SK3 peptide was added to the antibody solution at $1 \mu \mathrm{g} / 1 \mu \mathrm{g}$ antibody. OC, optic chiasm. Scale bar $=100 \mu \mathrm{m}$ in B (applies to A,B).
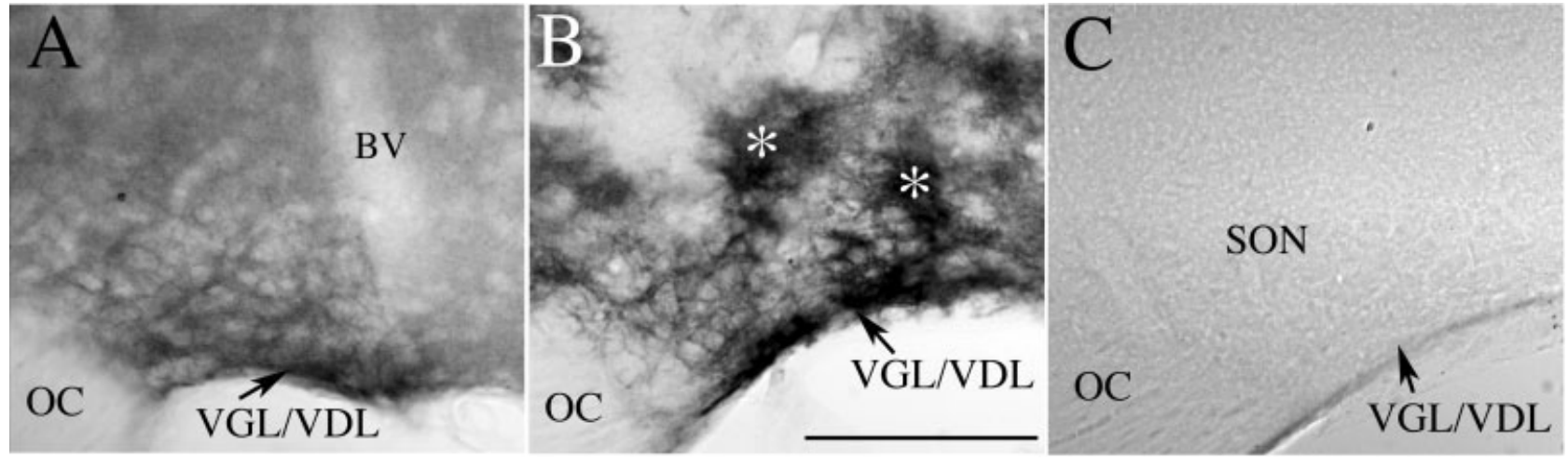

Fig. 2. Immunochemical localization of SK3 protein in the supraoptic nucleus (SON) of mice from $40-\mu \mathrm{m}$ coronal frozen sections using the $\mathrm{ABC}$ method with an antibody dilution of 1:500. A: Staining in the SON of a C57BI/6 wild-type mouse. Similar to rat, the reactivity is largely pericellular, and staining is denser in the ventral glial and dendritic lamina (VGL/VDL). B: Overexpression of SK3 protein from an untreated transgenic $\mathrm{SK}^{\mathrm{T} / \mathrm{T}}$ mouse. Although much denser than in

Digital images $(2,240 \times 2,944)$ were also acquired directly with a Hamamatsu ORCA camera and AMT Advantage (Danvers, MA) software. In both cases, figures were made in Adobe Photoshop with small adjustments in dynamic range.

\section{RESULTS \\ Light microscopic localization and specificity of SK3 immunoreactivity}

At dilutions of 1:500 to 1:2,000, the SK3 antibody gave consistent results in several animals $(n=10)$, as shown in Figure 1A. Optimal dilutions were 1:500 to 1:1,000. Immunoreactivity appeared densest in the pericellular regions and was extremely dense in the ventral glial/dendritic lamina (VGL or VDL, respectively). Absorption controls indicated a wild-type mice, staining is still heaviest between neurons and in the VGL. In addition, small patches of intense reactivity (*) are present in the SON and elsewhere in the brain. C: Absence of SK3 immunoreactivity in a DOX-treated $\mathrm{SK}^{\mathrm{T} / \mathrm{T}}$ mouse, confirming the specificity of the antibody for SK3 protein. OC, optic chiasm; BV, blood vessel. Scale bar $=100 \mu \mathrm{m}$ in B (applies to A-C).

specificity of the staining for the peptide (which represents the N-terminal, intracellular domain of human SK3) used to generate this antibody (Fig. 1B).

The lacy pattern of the reactivity, in which somata were pale relative to surrounding regions, was also evident in wild-type $C 57 B I / 6$ mice $(\mathrm{n}=4)$ stained with the same antibody (Fig. 2A). In homozygous SK3-targeted mice ( $\mathrm{T} / \mathrm{T} ; \mathrm{n}=4)$, SK3 was overexpressed throughout the brain, as previously reported (Bond et al., 2000). Although reaction product was much denser in the $\mathrm{T} / \mathrm{T}$ mice than in the wild type in the SON, the pericellular pattern of staining was still evident (Fig. 2B). In addition, in the SON and elsewhere, large, unevenly distributed masses of reaction product were evident, and cellular details were often difficult to detect. The specificity of the SK3 antibody for SK3 protein was confirmed by downregulation of the SK3 gene 
in DOX-treated T/T mice (Fig. 2C). In these animals ( $\mathrm{n}=$ 4), SK3 immunoreactivity was extremely weak or undetectable.

\section{Ultrastructural localization}

We used transmission electron microscopy to determine the location of DAB-labeled SK3 immunoreactivity in the $\mathrm{SON}$ in rats $(\mathrm{n}=5)$. Under light microscopy, the pattern of staining was similar despite the absence of detergent in the primary antibody solution. Thin sections through the SON confirmed that reaction product was largely adjacent to neurons (Fig. 3A) and to dendrites and axons in the VDL/VGL (Armstrong et al., 1982; Perlmutter et al., 1984). We cannot rule out the possibility that some of this reactivity could be located in the membranes of these neurons and their processes, but the pre-embedding method is not ideal for such precise localization as DAB reaction product can seed beyond its original deposition. Regardless, in most cases reaction product was extensive in the space between neurons and was located in glial-type processes. Such processes are frequently known to interpose among neurons and dendrites in the SON (Hatton, 2004; Theodosis et al., 2004). A small amount of reaction product was found within some magnocellular neurons or neuron-like processes.

\section{SK3 localization in substantia nigra}

The substantia nigra, pars compacta (SNC) is another region known to contain SK3 mRNA (Köhler et al., 1996; Stocker and Pedarzani, 2000; Tacconi et al., 2001) and an apamin-blockable mAHP (e.g., Seutin et al., 1993; Ping and Sheperd, 1996; Wolfart et al., 2001). SK3 expression is also prominent in the SNC, as judged by studies employing the same antibody as that used here (Tacconi et al., 2001; Fujita et al., 2003). We thus examined the SNC in order to compare the pattern of SK3 expression with that in the SON. As shown in Figure 4A and B, instead of the lacy pattern exhibited in the SON, SNC somata and dendrites were sharply labeled with SK3 immunoreactivity. Examination with the electron microscope confirmed that most of the reaction product was localized to SNC somata or dendrites (Fig. 4C,D), although some apparently glial processes were labeled as well.

\section{Co-localization of SK3 immunoreactivity with glial or neuronal antigens: confocal microscopy}

Sections of rat hypothalamus were reacted with SK3 antibody and mouse antibodies raised against VP- or OTneurophysin or GFAP $(n=7)$. Examples of double staining with the neuronal peptide antibodies are shown in Figures 5 and 6 . As with the DAB staining described above, extensive pericellular SK3 immunofluorescence was the dominant pattern, and this was true of either VP (Fig. 5) or OT (Fig. 6) neurons. Some somata were lightly stained with SK3 antibody. This weak somatic staining likewise showed as just a few spots of co-localization in merged files. However, some intense areas of colocalization were found at the perimeter of some neurons and in some thick processes (probable dendrites).

A more striking and consistent pattern of co-localization was present after reaction with SK3 and GFAP antibodies (Fig. 7). As reported previously (Salm et al., 1985; Bonfanti et al., 1993), GFAP-positive processes were found extensively among neuronal somata and dendrites in the
SON and were intimately associated with blood vessels. These processes were either long and narrow or in other cases appeared as vellate expansions. As shown in Figure 7 , the ventral region of the SON was so densely stained with GFAP that individual elements, processes, or somata were difficult to discern. This region also contains many VP and OT dendrites, especially just dorsal to the densest glial labeling (Figs. 5, 6). The degree of co-localization was more apparent with increased magnification (Fig. 7D-I). This is largely due to the difficulty in adjusting the dynamic range of lower power micrographs to bring up faint processes, because the ventral lamina was so intensely stained. With a $100 \times$ objective, a great majority of both fine and densely labeled GFAP-positive processes were double-labeled with the SK3 antibody (Fig. 6G-I).

\section{DISCUSSION}

Apamin-sensitive AHPs are clearly important for SON neuronal function (Bourque and Brown, 1987; Armstrong et al., 1994; Kirkpatrick and Bourque, 1996; Greffrath et al., 2004 ), and the present study confirms work suggesting these are underlain by SK3 channels as determined by in situ hybridization (Stocker and Pedarzani, 2000; Tacconi et al., 2001) and immunochemistry (Greffrath et al., 2004). Our new finding is that within the SON, SK3 immunoreactivity is much more strongly associated with GFAP-positive astrocytes than it is with neurons. This difference may relate to the typically low input resistance of astrocytes (especially when electrically coupled); a high density of $\mathrm{CA}^{2+}$. dependent $\mathrm{K}^{+}$channels may be needed in order to effectively hyperpolarize the membrane effectively. On the other hand, the high input resistance of SON neurons, $\sim 1 \mathrm{G} \Omega$ in whole cell recordings (Stern et al., 1999), suggests that relatively few SK3 channels could produce very effective AHPs. Furthermore, we often observed co-localization of SK3 in the dendrites of SON neurons, suggesting that these channels could be differentially distributed in dendrites vs. soma in these neurons. However, $\mathrm{CA}^{2+}$-dependent $\mathrm{K}^{+} \mathrm{AHPs}$ also are found in dissociated SON neurons (Oliet and Bourque, 1992); therefore at least some of the channels are on the soma or on proximal dendritic membrane.

For comparison, we also examined the SNC and found that in agreement with previous studies using the same antibody, SK3 reactivity is strongly localized to the SNC (Tacconi et al., 2001; Fujita et al., 2003). Like the SON, these observations correlate with mRNA distribution (Köhler et al., 1996; Stocker and Pedarzani, 2000; Tacconi et al., 2001) and the apamin-sensitivity of an mAHP (Seutin et al., 1993; Wolfart et al., 2003). In the SNC, SK3 reactivity is much stronger in neurons than the weak reactivity we found in the SON neurons, at the same concentration of antibody. It should be noted that SON neurons typically require spike trains to evoke an apaminblockable mAHP (Kirkpatrick and Bourque, 1996), whereas SNC neurons exhibit these mAHPS after individual spikes, even after subthreshold oscillations. Although some aspect of this difference could be related to differences in $\mathrm{CA}^{2+}$ channel density, the immunochemical data also suggest that SNC neurons express SK3 protein more strongly than do SON neurons.

An examination of Figure 7B of Stocker and Pedarzani (2000) reveals that a high density of SK3 mRNA is also located ventral to the SON, near the pial surface, in addition to product in the SON proper. The observed reaction would be consistent with our observation of SK3 in 

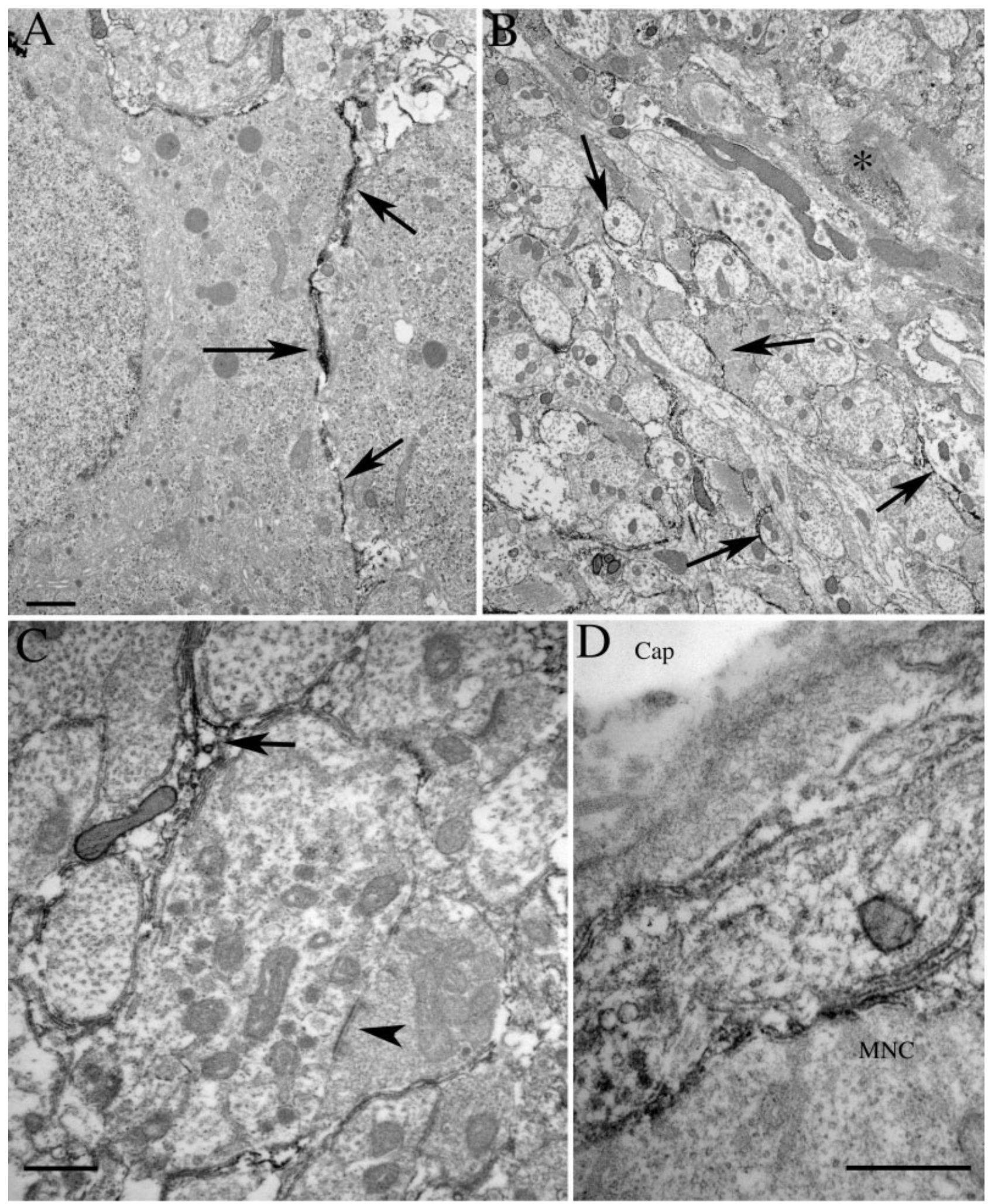

Fig. 3. Ultrastructural localization of SK3 immunoreactivity in rat SON using the pre-embedding, ABC method. A: Reaction product between two somata (arrows). B: Reaction product in the ventral dendritic/glial lamina of the SON. The product appears densest in small processes between dendrites or axons (arrows). Occasionally larger profiles contain product $(*)$, but these are not similar in morphology to the many axons and dendrites and are probably glia.
C: Higher magnification of neuropil in the SON showing reaction product in a glial process (arrow) surrounding a dendrite that contains dense-core granules typical of the magnocellular neurons. This dendrite receives a synapse (arrowhead). D: Glial cell process labeled near a capillary (Cap) in the SON and also adjacent to a magnocellular neuron soma (MCN). Scale bars $=1 \mu \mathrm{m}$ in A (applies to A,B); 500 $\mathrm{nm}$ in $\mathrm{C}, \mathrm{D}$. 

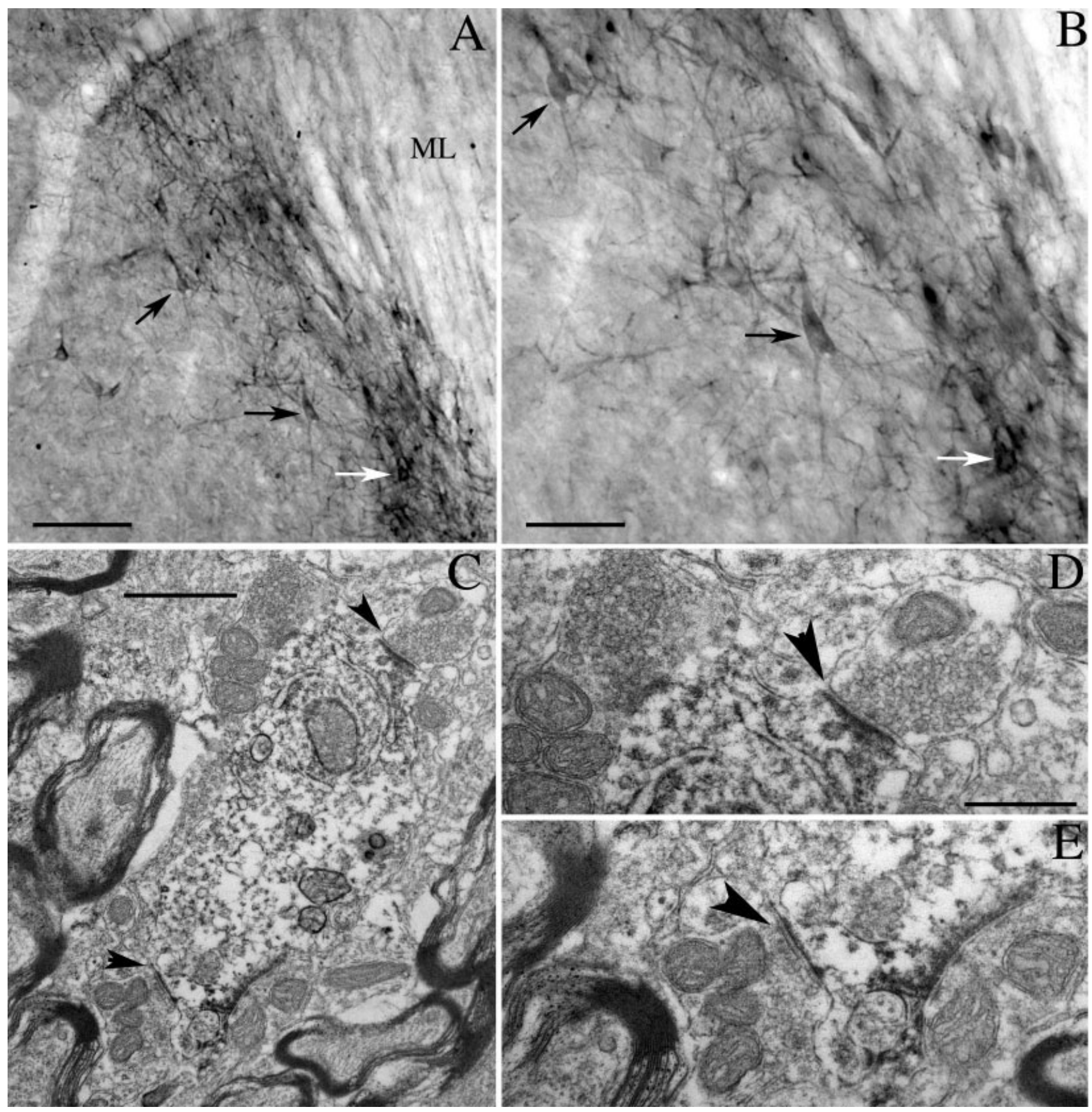

Fig. 4. Light and electron microscopic localization of SK3 reaction product in the substantia nigra, pars compacta (SNC) of rat. A: Several reactive SNC neurons (examples are indicated with arrows) lateral to the medial lemniscus (ML) in a coronal section through the midbrain. In contrast to the lacy appearance of SK3 reactivity in the SON, SNC neurons are clearly labeled. B: Higher magnification of

astrocytes in the VDL/VGL, but it could also relate to dendritic mRNA, because this region is dense with dendrites from SON neurons (Armstrong et al., 1982). Although reports of electrophysiological studies in vitro have noted the presence of $\mathrm{CA}^{2+}$-dependent $\mathrm{K}^{+}$currents in neuroglia (Barres et al., 1990), including apaminblockable currents (Burnard et al., 1990; Jalonen et al., 1997; Bychkov et al., 2001), and although specific apamin
SNC shown in A, with the same three indicated neurons (arrows) for reference. C: Electron micrograph of labeled SNC proximal dendrite receiving two synapses (arrowheads). D,E: The synapses indicated in $\mathrm{C}$ are shown at higher magnification (arrowheads). Scale bars $=100$ $\mu \mathrm{m}$ in $\mathrm{A} ; 50 \mu \mathrm{m}$ in $\mathrm{B} ; 1 \mu \mathrm{m}$ in $\mathrm{C} ; 500 \mathrm{~nm}$ in $\mathrm{D}$ (applies to $\mathrm{D}, \mathrm{E}$ ).

binding sites on astrocyte membranes have been found (Seagar et al., 1987), there has been little investigation of the presence of SK-type channels in astrocytes in situ. A notable exception is a recent report demonstrating SK3like immunoreactivity in the glia investing olfactory nerve fascicles in the olfactory bulb (Fujita et al., 2003).

The presence of $\mathrm{CA}^{2+}$-dependent $\mathrm{K}^{+}$and other $\mathrm{K}^{+}$ channels (like inward rectifiers) in astrocytes is consid- 

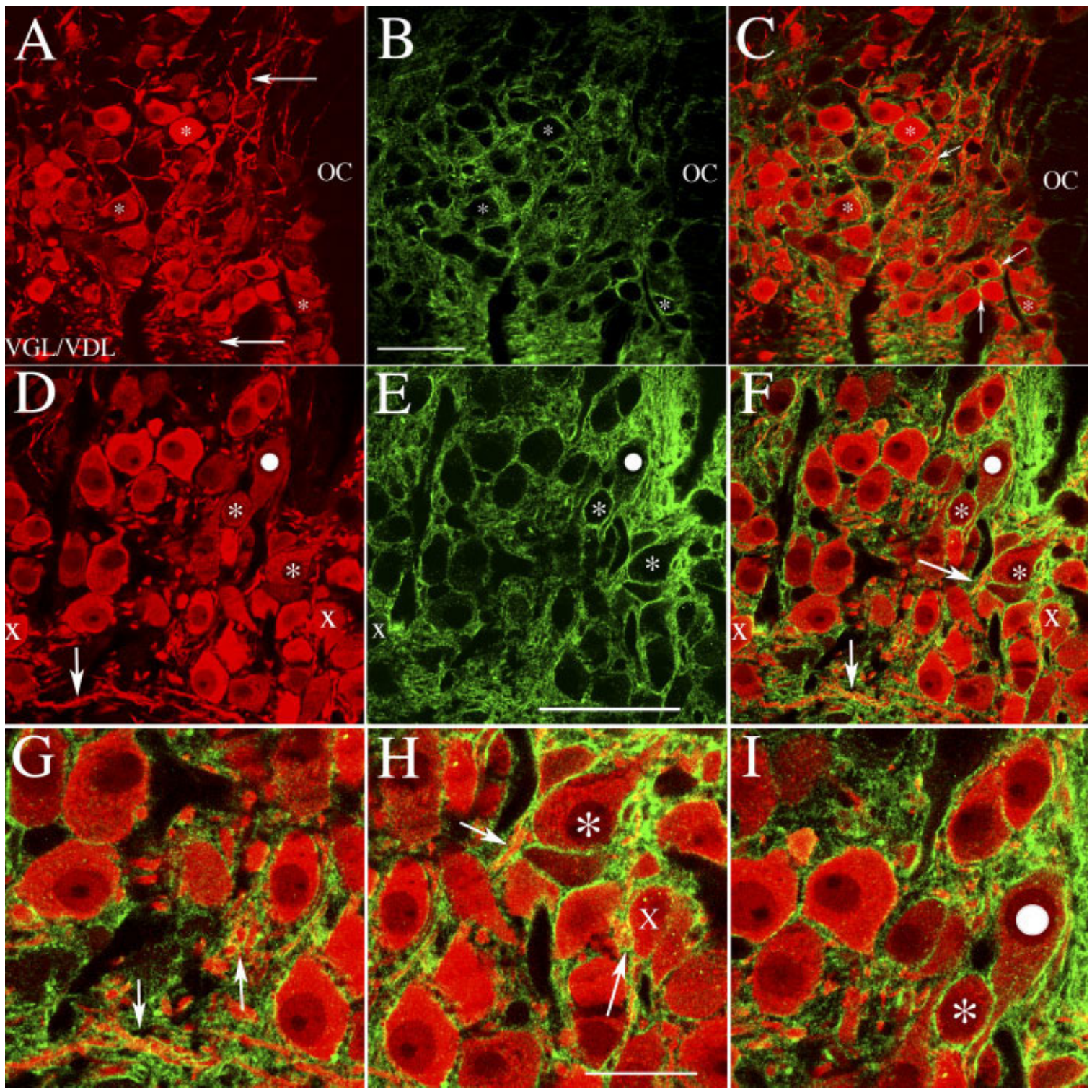

Fig. 5. Co-localization of SK3 and VP-neurophysin (VP-NP) immunoreactivity in coronal $1-\mu \mathrm{m}$ optical sections of rat SON using a confocal microscope. A-C: $40 \times$ objective. A: VP-NP immunoreactivity labeled with Texas Red-conjugated secondary antibody. Stained neurons $(*)$ and thick processes (arrows) are visible. B: SK3 immunoreactivity labeled with fluorescein-conjugated secondary antibody in the same section and image plane as in A. Note the strong pericellular distribution. Some of the VP neurons from A are indicated (*). C: The images in A and B merged. Overlap of the FITC- and Texas Redlabeled elements indicated by yellow. In general, SK3 labeling is not associated with VP-NP labeling. However, there is some overlap at the edges of some neurons and within some processes (arrows). D-F: Higher magnification (60× objective) of VP-NP and SK3 immunoreactivity in another section. Asterisks indicate stained neurons with little co-localization. Neurons labeled "X" co-localize the two products on their perimeter, whereas the neuron labeled with a filled circle has

ered important to their potent ionic buffering activity during periods of high neuronal activity (Sontheimer, 1994). Although not studied in the SON, another variety of $\mathrm{CA}^{2+}$-dependent $\mathrm{K}^{+}$channel, $r S l o$, has been localized to astrocyte endfeet along blood vessels and the pia limitans light SK3 over the soma. A thick dendritic-like process in the VGL VDL has considerable co-localization (arrow). D: VP-NP immunoreactivity. E: SK3 immunoreactivity. F: The images in D and E merged. Overlap is indicated by yellow. G-I: Digital zooms $(\times 2)$ of cells in merged image shown in F. G: The horizontal VP dendrite (downward arrow) has streaks of SK3 staining. Processes indicated by upward arrow have SK3 reactivity on their perimeter. H: Two neurons are indicated from the right half of $\mathrm{F}$, one with some co-localization (X) and one surrounded by SK3 staining but not double labeled (*). Arrows point to co-localization in some processes. I: From the upper right portion of $\mathrm{F}$. Light co-localization is evident in the neuron indicated with the filled circle, whereas another neuron is ringed with SK3 reactivity, but not double stained (*). OC, optic chiasm; VGL/ VDL, ventral glia and dendritic lamina. Scale bars $=50 \mu \mathrm{m}$ in $\mathrm{B}$ (applies to A-C); $25 \mu \mathrm{m}$ in E (applies to D-F); $10 \mu \mathrm{m}$ in $\mathrm{H}$ (applies to G-I).

in the rat brain (Price et al., 2002), where it could dump $\mathrm{K}^{+}$from neuronal areas in response to increases in $\left[\mathrm{CA}^{2+}\right]_{\mathrm{i}}$. In the present study, SK3 staining in SON astrocytes did not appear to be strongly polarized in the same manner as rSlo appears to be in the hippocampus, for 


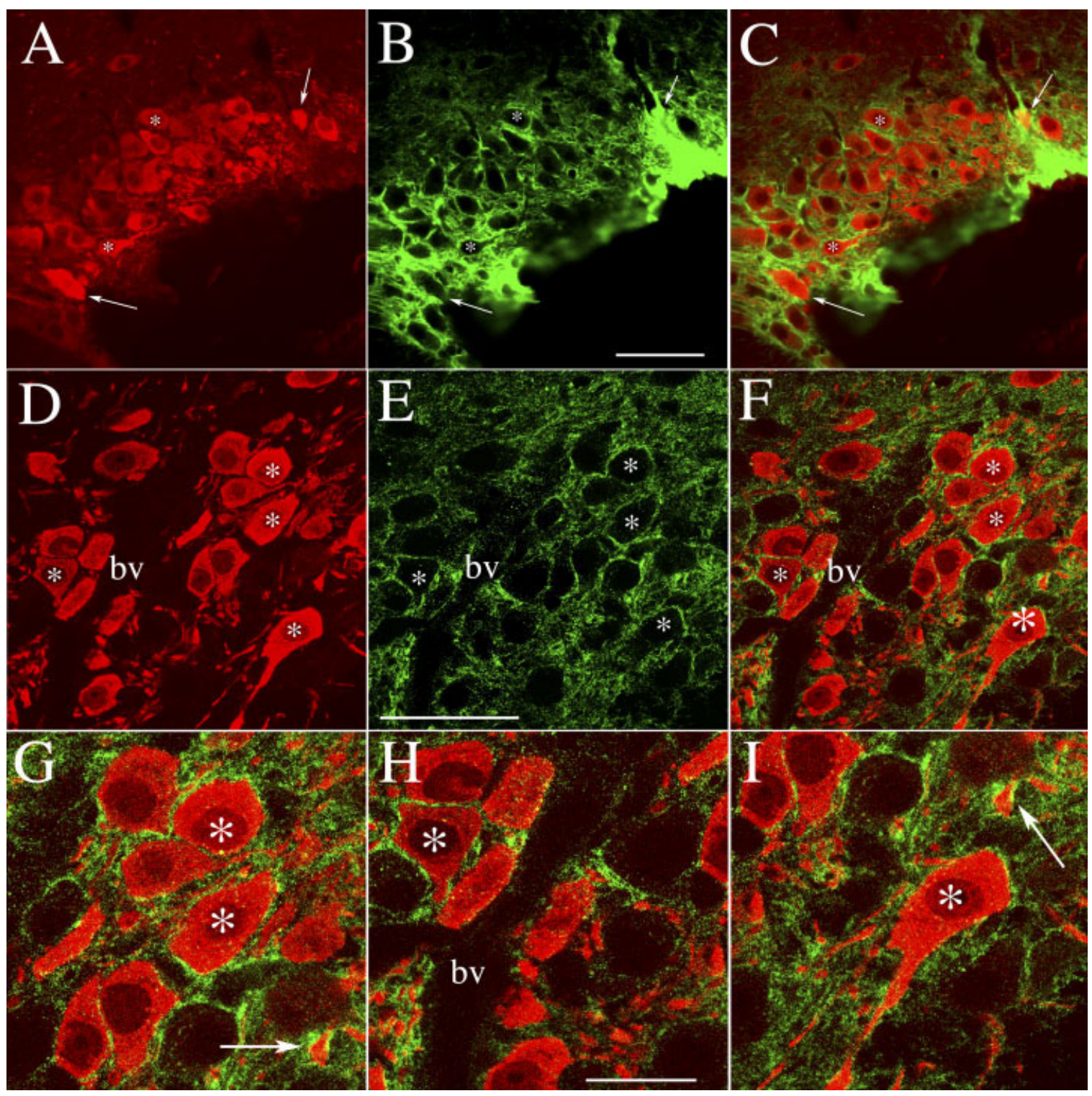

Fig. 6. Co-localization of SK3 and OT-neurophysin (OT-NP) immunoreactivity in coronal $1-\mu \mathrm{m}$ optical sections of rat SON using a confocal microscope. A-C: $40 \times$ objective. A: OT-NP immunoreactivity labeled with Texas Red-conjugated secondary antibody. Two neurons (*) are shown in B and C to have no SK3 reactivity whereas two others (arrows) have some SK3 reactivity (see B and C). B: SK3 immunoreactivity labeled with fluorescein-conjugated secondary antibody in the same section and image plane as in A. Note the strong pericellular distribution. Two of the OT neurons from A are indicated (*) that have no SK3 reactivity, whereas two neurons have SK3 reactivity (arrows), one strongly (arrow on the right). C: The images in A and B merged. Overlap of the FITC- and Texas Red-labeled elements indicated by yellow. Most SK3 labeling is not associated with OT-NP labeling, but one cell shows extensive overlap (arrow on the right) and another weak double labeling (arrow on the left). The right neuron also appears to be associated with an intense SK3-labeled process dorsally that is not OT-NP positive. Otherwise, SK3 reactivity remains peri- cellular, as indicated for two neurons (*). D-F: Higher magnification (60× objective) of OT-NP and SK3 immunoreactivity in another section. Asterisks indicate stained neurons with little co-localization Note large blood vessel (bv). D: OT-NP immunoreactivity. E: SK3 immunoreactivity. F: The images in D and E merged. Overlap is indicated by yellow, and little is visible at this scale. G-I: Digital zooms $(\times 2)$ of image in D-F. G: Two neurons $\left(^{*}\right)$ in the right half of the area shown in D-F are evident, and little co-localization is seen. A process beneath these two neurons exhibits a small amount of peripheral co-localization (arrow). H: A neuron (*) from the left half of the area shown in D, near a blood vessel (bv), is surrounded by SK3 immunoreactivity but has no co-localization. I: A neuron (*) with a long ventral process from the lower right half of the area shown in D-F. At this magnification, a small degree of co-localization is evident, mostly at the perimeter of the process and soma. The process shown in $\mathrm{G}$ (arrow) is also visible. Scale bars $=15 \mu \mathrm{m}$ in B (applies to A-C); $25 \mu \mathrm{m}$ in E (applies to D-F); $10 \mu \mathrm{m}$ in $\mathrm{H}$ (applies to G-I). example, where staining appears to be limited to the endfeet (Price et al., 2002). SK3 channels could nevertheless participate in altering local blood flow by redistributing $\mathrm{K}^{+}$during periods of increased neuronal activity, or in direct response to neurotransmitters that elevate $\left[\mathrm{CA}^{2+}\right]_{\mathrm{i}}$.
In the SON, buffering of extracellular $\mathrm{K}^{+}$is highly effective during intense neuronal activity (Coles and Poulain, 1991). Elevation of extracellular $\left[\mathrm{K}^{+}\right]$near blood vessels can also act as one of many signaling factors leading to vasodilation and concomitant increases in local cerebral 

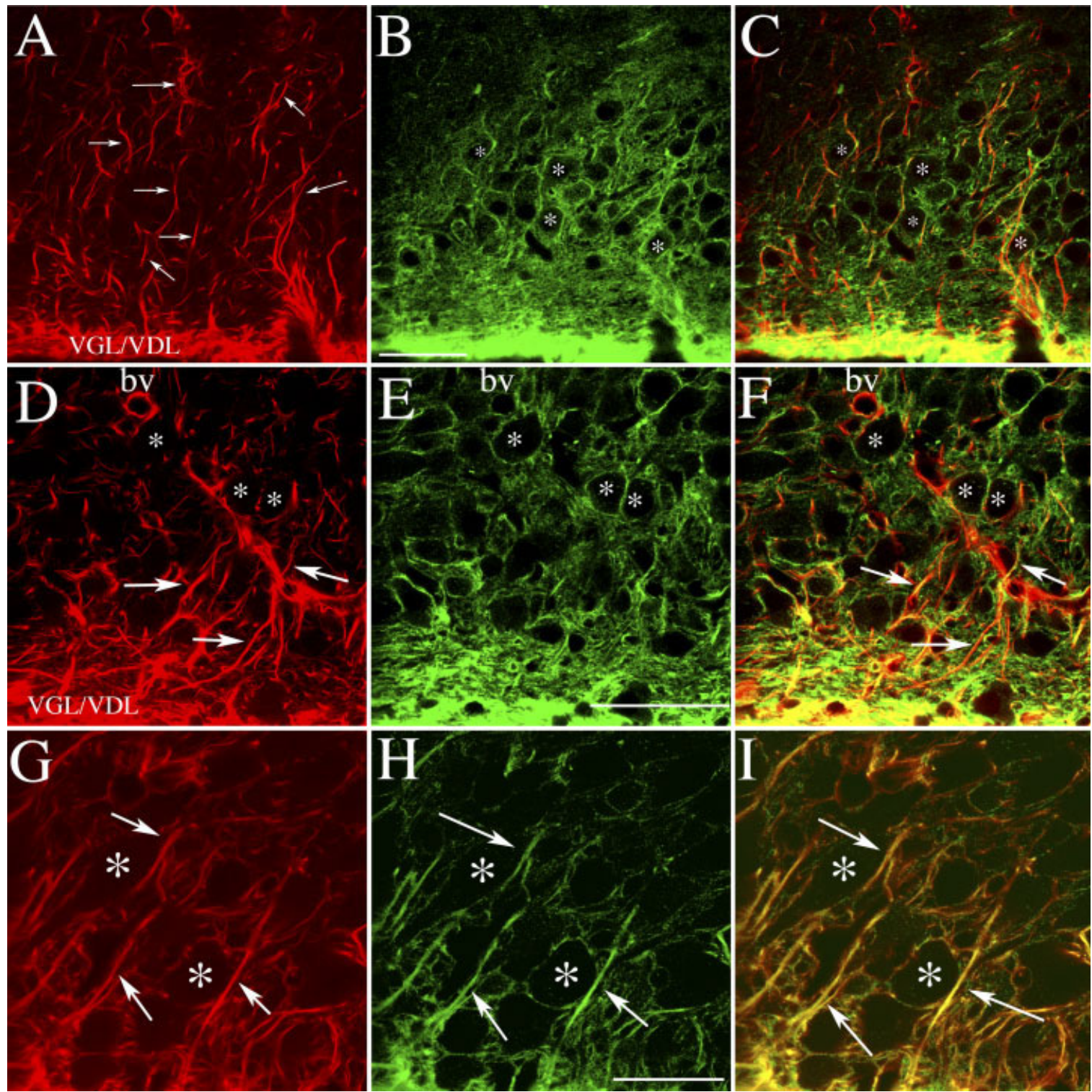

Fig. 7. Co-localization of GFAP and SK3 immunoreactivity in coronal $1-\mu \mathrm{m}$ optical sections of rat SON using a confocal microscope. A-C: $40 \times$ objective. A: GFAP immunoreactivity. GFAP is densely distributed in the VGL/VDL and in many processes coursing through the SON (arrows). B: SK3 immunoreactivity labeled with fluoresceinconjugated secondary antibody in the same section and image plane as in A. SK3 forms a lacy network around somata (*) and is densely distributed in the VGL/VDL (compare with A). C: The images in A and B merged. Overlap of the FITC- and Texas Red-labeled elements indicated by yellow. Much of the SK3 labeling is co-localized with GFAP processes. Note the strong co-localization in the VGL/VDL. Many neurons have a thin rim of co-localized GFAP-SK3 (*). D-F: Higher magnification $(40 \times$ objective) in another section. D: GFAP immunoreactivity. GFAP-positive processes (arrows) and outlined somata $(*)$ are indicated. A densely reactive blood vessel wall (bv) is also visible. Note the dense GFAP staining in the VGL/VDL. E: SK3

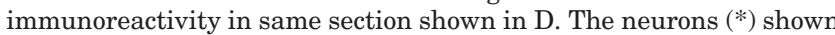
in $\mathrm{D}$ are indicated. Note the dense SK3 immunoreactivity in the

blood flow during increased neuronal activity (Nelson and Quayle, 1995).

As elsewhere, SON astrocytes can modify extracellular transmitter levels by virtue of membrane transporters,
VGL/VDL (see D for reference). F: The images in A and B merged. Overlap of the FITC- and Texas Red-labeled elements indicated by yellow. Much of the SK3 labeling is co-localized with GFAP processes, especially in the VGL/VDL. The GFAP processes indicated in D (arrows) have considerable co-localization. Some neurons $(*)$ are likewise surrounded by SK3 and GFAP immunoreactivity. G-H: Higher magnification (100× objective) of GFAP and SK3 immunoreactivity in another section. G: GFAP immunoreactivity. Note that many more fine processes are visible at high magnification, surrounding unstained neurons $(*)$. A few prominent processes are indicated with arrows. H: SK3 immunoreactivity. SK3 immunoreactivity largely surrounds negative somata (*). The processes indicated in $\mathrm{G}$ are again shown with arrows. I: The images in $\mathrm{G}$ and $\mathrm{H}$ merged. Overlap of the FITC- and Texas Red-labeled elements indicated by yellow. Note that the majority of GFAP processes have SK3 immunoreactivity. Examples from $\mathrm{G}$ and $\mathrm{H}$ are indicated with arrows. VGL/VDL, ventral glia and dendritic lamina. Scale bar $=25 \mu \mathrm{m}$ in B (applies to A-C), E (applies to D-F), H (applies to G-I).

such as those for glutamate, and the extent of their process distribution in the SON correlates with their ability to control presynaptic activity (Oliet et al., 2001). However, SON astrocytes are heterogeneous both morpholog- 
ically (Bonfanti et al., 1993; Israel et al., 2003) and physiologically (Israel et al., 2003). Radial glial cells contain both GFAP and vimentin (Bonfanti et al., 1993) and possess $\gamma$-aminobutyric acid (GABA) ${ }^{-}$-type receptors but do not respond to glutamate or appear to have the glutamate transporter (Israel et al., 2003). In contrast, smaller, stellate astrocytes show little GFAP reactivity but possess glutamate receptors and glutamate transporters (Israel et al., 2003). The significant amount of pericellular SK3 staining we observed that was not associated with VP- or OT-neurophysin or GFAP-positive processes may represent staining on this class of astrocyte. Alternatively, there is a heterogeneous distribution of GFAP within any particular astrocyte, and immunoreactivity is influenced by the relative presence of dissociated vs. bundled intermediate filaments (Eng et al., 1989). An apparent mismatch of GFAP immunoreactivity at the light microscopic level and glial cell process distribution ultrastructurally has been noted in the SON previously (see Hawrylak et al., 1998, for discussion).

Astrocytes in the SON have an intimate and functionally dynamic association with neurons (Salm et al., 1998; Hatton, 2004; Theodosis et al., 2004). They respond morphologically to stimuli activating hormone release with process withdrawal that is correlated with increasing neuronal apposition and synaptogenesis. This dramatic change may be the primary cause of the reductions in tortuosity and extracellular volume seen during lactation in the SON (Piet et al., 2004). In addition, astrocytes actively suppress SON neuronal activity by secreting the inhibitory transmitter taurine during hypotonicity, and they release this inhibition by secreting less taurine during hypertonicity, a stimulus known to depolarize and activate SON neurons (Hussy et al., 2000). This osmosensitivity may be related to the high density of aquaoporin-4 water channels found on SON astrocytes (Nielsen et al., 1997). Water flux to and from astrocytes would be an important homeostatic mechanism to counterbalance $\mathrm{K}^{+}$ flux after periods of high neuronal activity (Niermann et al., 2001).

Given the relative absence of spiking and dearth of high-voltage $\mathrm{CA}^{2+}$ channels in astrocytes, changes in intracellular $\left[\mathrm{CA}^{2+}\right]$ from $\mathrm{CA}^{2+}$ stores are a likely factor in the control $\mathrm{CA}^{2+}$-dependent $\mathrm{K}^{+}$channels. Astrocytes respond to a variety of neurotransmitters receptors with changes in $\left[\mathrm{CA}^{2+}\right]_{\mathrm{i}}$ (Fellin and Carmignoto, 2004). Although not yet observed specifically in SON astrocytes, receptors for VP appear in cortical (Yamazaki et al., 1997) and spinal cord (Hosli et al., 1991; Hosli and Hosli, 1992) astrocytes in culture, and OT receptors are also present in cortical and hypothalamic astrocytes (Di Scala-Guenot and Strosser, 1992). As in SON neurons (e.g., Lambert et al., 1994), VP or OT receptor activation results in increases in astrocytes $\left[\mathrm{CA}^{2+}\right]_{\mathrm{i}}$ (Di Scala-Guenot et al., 1994; Zhao and Brinton, 2002), and VP activation has further been shown to alter water flux in the brain (Niermann et al., 2001; Simard and Nedergaard, 2004). Likewise, the specialized astrocyte of the neurohypophysis, the pituicyte, has functional VP receptors linked to $\left[\mathrm{CA}^{2+}\right]_{\mathrm{i}}$ (Hatton et al., 1992) and cell morphology (Rosso et al., 2004). It is noteworthy that restricting $\mathrm{CA}^{2+}$ influx through $\mathrm{CA}^{2+}$-permeable AMPA receptors on Bergmann glia in the cerebellum dramatically alters the morphological relationship of these astrocytes with Purkinje cell dendrites (Iino et al., 2001). Because OT and VP are clearly released from dendrites within the SON (Ludwig,
1998), we may speculate that these peptides as well as other transmitters could modulate $\mathrm{K}^{+}$buffering and water flux, as well as astrocyte morphology, via actions on astrocytes that are mediated through changes in $\left[\mathrm{CA}^{2+}\right]_{\mathrm{i}}$.

\section{ACKNOWLEDGEMENTS}

Monoclonal antibodies to oxytocin- (PS 36) and vasopressin-neurophysin (PS 41) were provided by Dr. Hal Gainer (National Institutes of Health, Bethesda, MA).

\section{LITERATURE CITED}

Armstrong WE, Schöler J, McNeill TH. 1982. Immunocytochemical, Golgi and electron microscopic characterization of putative dendrites in the ventral glial lamina of the rat supraoptic nucleus. Neuroscience 7:679694.

Armstrong WE, Smith BN, Tian M. 1994. Electrophysiological characteristics of immunochemically identified rat oxytocin and vasopressin neurones in vitro. J Physiol 475:115-128.

Armstrong WE, Rubrum A, Teruyama R. 2003. Immunochemical localization of SK3-like, calcium-dependent potassium channels in astrocytes of the rat supraoptic nucleus (SON). Abstr Soc Neurosci Abstr 612.16.

Barres BA, Chun LL, Corey DP. 1990. Ion channels in vertebrate glia. Annu Rev Neurosci 13:441-474.

Ben-Barak Y, Russell JT, Whitnall MH, Ozato K, Gainer H. 1985. Neurophysin in the hypothalamo-neurohypophysial system. I. Production and characterization of monoclonal antibodies. J Neurosci 5:81-97.

Bond CT, Sprengel R, Bissonnette JM, Kaufmann WA, Pribnow D, Neelands T, Storck T, Baetscher M, Jerecic J, Maylie J, Knaus HG, Seeburg PH, Adelman JP. 2000. Respiration and parturition affected by conditional overexpression of the $\mathrm{Ca}^{2+}$-activated $\mathrm{K}^{+}$channel subunit, SK3. Science 289:1942-1946.

Bond CT, Herson PS, Strassmaier T, Hammond R, Stackman R, Maylie J, Adelman JP. 2004. Small conductance $\mathrm{Ca}^{2+}$-activated $\mathrm{K}^{+}$channel knock-out mice reveal the identity of calcium-dependent afterhyperpolarization currents. J Neurosci 24:5301-5306.

Bonfanti L, Poulain DA, Theodosis DT. 1993. Radial glia-like cells in the supraoptic nucleus of the adult rat. J Neuroendocrinol 5:1-5.

Bourque C, Brown DA. 1987. Apamin and d-tubocurarine block the afterhyperpolarization of rat supraoptic neurosecretory neurons. Neurosci Lett 82:185-190.

Burnard DM, Crichton SA, MacVicar BA. 1990. Electrophysiological properties of reactive glial cells in the kainate-lesioned hippocampal slice. Brain Res 510:43-52.

Bychkov R, Glowinski J, Giaume C. 2001. Sequential and opposite regulation of two outward $\mathrm{K}(+)$ currents by ET-1 in cultured striatal astrocytes. Am J Physiol Cell Physiol 281:C1373-1384.

Coles JA, Poulain DA. 1991. Extracellular $\mathrm{K}^{+}$in the supraoptic nucleus of the rat during reflex bursting activity by oxytocin neurones. J Physiol 439:383-409.

Crowley WR, Armstrong WE. 1992. Neurochemical regulation of oxytocin secretion in lactation. Endocrine Rev 13:33-65.

Debus E, Weber K, Osborn M. 1983. Monoclonal antibodies specific for glial fibrillary acidic (GFA) protein and for each of the neurofilament triplet polypeptides. Differentiation 25:193-203.

Di Scala-Guenot D, Strosser MT. 1992. Oxytocin receptors on cultured astroglial cells. Kinetic and pharmacological characterization of oxytocin-binding sites on intact hypothalamic and hippocampic cells from foetal rat brain. Biochem J 284:491-497.

Di Scala-Guenot D, Mouginot D, Strosser MT. 1994. Increase of intracellular calcium induced by oxytocin in hypothalamic cultured astrocytes. Glia 11:269-276.

Eng LF, D'Amelio FE, Smith ME. 1989. Dissociation of GFAP intermediate filaments in EAE: observations in the lumbar spinal cord. Glia 2:308317.

Fellin T, Carmignoto G. 2004. Neurone-to-astrocyte signalling in the brain represents a distinct multifunctional unit. J Physiol 559:3-15.

Franke FE, Schachenmayr W, Osborn M, Altmannsberger M. 1991. Unexpected immunoreactivities of intermediate filament antibodies in human brain and brain tumors. Am J Pathol 139:67-79.

Fujita A, Takeuchi T, Hanai J, Hata F. 2003. Expression of the small conductance $\mathrm{Ca}^{2+}$-activated $\mathrm{K}^{+}$channel, SK3, in the olfactory ensheathing glial cells of rat brain. Cell Tissue Res 313:187-193. 
Ghamardi-Langroudi M, Bourque CW. 2004. Muscarinic receptor modulation of slow after hyperpolarization and phasic firing in rat supraoptic nucleus neurons. J Neurosci 24:7718-7726.

Greffrath W, Martin E, Reuss S, Boehmer G. 1998. Components of afterhyperpolarization in magnocellular neurones of the rat supraoptic nucleus in vitro. J Physiol 513:493-506.

Greffrath W, Magerl W, Disque-Kaiser U, Martin E, Reuss S, Boehmer G. 2004. Contribution of $\mathrm{Ca}^{2+}$-activated $\mathrm{K}^{+}$channels to hyperpolarizing after-potentials and discharge pattern in rat supraoptic neurones. J Neuroendocrinol 16:577-588.

Hatton GI. 2004. Morphological plasticity of astroglial/neuronal interactions: functional implications. In: Hatton GI, Parpura V, editors. Glialneuronal signaling. Amsterdam: Kluwer. p 99-124.

Hatton GI, Bicknell RJ, Hoyland J, Bunting R, Mason WT. 1992. Arginine vasopressin mobilises intracellular calcium via v1-receptor activation in astrocytes (pituicytes) cultured from adult rat neural lobes. Brain Res 588:75-83.

Hawrylak N, Fleming JC, Salm AK. 1998. Dehydration and rehydration selectively and reversibly alter glial fibrillary acidic protein immunoreactivity in the rat supraoptic nucleus and subjacent glial limitans. Glia 22:260-271.

Hosli E, Hosli L. 1992. Autoradiographic localization of binding sites for arginine vasopressin and atrial natriuretic peptide on astrocytes and neurons of cultured rat central nervous system. Neuroscience 51:159 166.

Hosli L, Hosli E, Lefkovits M, Wagner S. 1991. Electrophysiological evidence for the existence of receptors for endothelin and vasopressin on cultured astrocytes of rat spinal cord and brainstem. Neurosci Lett 131:193-195.

Hussy N, Deleuze C, Desarmenien MG, Moos FC. 2000. Osmotic regulation of neuronal activity: a new role for taurine and glial cells in a hypothalamic neuroendocrine structure. Prog Neurobiol 62:113-134.

Iino M, Goto K, Kakegawa W, Okado H, Sudo M, Ishiuchi S, Miwa A, Takayasu Y, Saito I, Tsuzuki K, Ozawa S. 2001. Glia-synapse interaction through $\mathrm{Ca}^{2+}$-permeable AMPA receptors in Bergmann glia. Science 292:926-929.

Israel JM, Schipke CG, Ohlemeyer C, Theodosis DT, Kettenmann H. 2003. $\mathrm{GABA}_{\mathrm{A}}$ receptor-expressing astrocytes in the supraoptic nucleus lack glutamate uptake and receptor currents. Glia 44:102-110.

Jalonen TO, Margraf RR, Wielt DB, Charniga CJ, Linne ML, Kimelberg HK. 1997. Serotonin induces inward potassium and calcium currents in rat cortical astrocytes. Brain Res 758:69-82.

Kirkpatrick K, Bourque CW. 1996. Activity dependence and functional role of the apamin-sensitive $\mathrm{K}^{+}$current in rat supraoptic neurones in vitro. J Physiol 494:389-398.

Köhler M, Hirschberg B, Bond CT, Kinzie JM, Marrion NV, Maylie J, Adelman JP. 1996. Small-conductance, calcium-activated potassium channels from mammalian brain. Science 273:1709-1714.

Lambert RC, Dayanithi G, Moos FC, Richard P. 1994. A rise in the intracellular $\mathrm{Ca}^{2+}$ concentration of isolated rat supraoptic cells in response to oxytocin. J Physiol 478:275-287.

Ludwig M. 1998. Dendritic release of vasopressin and oxytocin. J Neuroendocrinol 10:881-895.

Nelson MT, Quayle JM. 1995. Physiological roles and properties of potassium channels in arterial smooth muscle. Am J Physiol 268:C799C822.

Nielsen S, Nagelhus EA, Amiry-Moghaddam M, Bourque C, Agre P, Ottersen OP. 1997. Specialized membrane domains for water transport in glial cells: high-resolution immunogold cytochemistry of aquaporin-4 in rat brain. J Neurosci 17:171-180.

Niermann H, Amiry-Moghaddam M, Holthoff K, Witte OW, Ottersen OP. 2001. A novel role of vasopressin in the brain: modulation of activitydependent water flux in the neocortex. J Neurosci 21:3045-3051.

Oliet SH, Bourque CW. 1992. Properties of supraoptic magnocellular neurones isolated from the adult rat. J Physiol 455:291-306.

Oliet SH, Piet R, Poulain DA. 2001. Control of glutamate clearance and synaptic efficacy by glial coverage of neurons. Science 292:923-926.

Perlmutter LS, Tweedle CD, Hatton GI. 1984. Neuronal/glial plasticity in the supraoptic dendritic zone: dendritic bundling and double synapse formation at parturition. Neuroscience 13:769-779.

Piet R, Vargova L, Sykova E, Poulain DA, Oliet SH. 2004. Physiological contribution of the astrocytic environment of neurons to intersynaptic crosstalk. Proc Natl Acad Sci U S A 101:2151-2155.

Ping H, Shepard P. 1996. Apamin-sensitive Ca21-activated K1 channels regulate pacemaker activity in nigral dopamine neurons. Neuroreport 73:809-814.
Poulain DA, Wakerley JB. 1982. Electrophysiology of hypothalamic magnocellular neurones secreting oxytocin and vasopressin. Neuroscience 7:773-808.

Price DL, Ludwig JW, Mi H, Schwarz TL, Ellisman MH. 2002. Distribution of rSlo $\mathrm{Ca}^{2+}$-activated $\mathrm{K}^{+}$channels in rat astrocyte perivascular endfeet. Brain Res 956:183-193.

Roper P, Callaway J, Shevchenko T, Teruyama R, Armstrong W. 2003 AHP's, HAP's and DAP's: how potassium currents regulate the excitability of rat supraoptic neurones. J Comput Neurosci 15:367-389.

Rosso L, Peteri-Brunback B, Mienville JM. 2004. Putative physiological significance of vasopressin $\mathrm{V}_{1 \mathrm{a}}$ receptor activation in rat pituicytes. J Neuroendocrinol 16:313-318.

Salm AK, Smithson KG, Hatton GI. 1985. Lactation-associated redistribution of the glial fibrillary acidic protein within the supraoptic nucleus. An immunocytochemical study. Cell Tissue Res 242:9-15.

Salm AK, Bobak J, Hawrylak N, Hatton GI, Aoki C. 1998. Evidence from around the brain for structural plasticity of astrocytes in the adult CNS. In: Laming P, Sykova E, Reichenbach A, Hatton G, Bauer H, editors. Glial Contributions to Behavior. Cambridge: Cambridge University Press, p 291-314.

Seagar MJ, Marqueze B, Couraud F. 1987. Solubilization of the apamin receptor associated with a calcium-activated potassium channel from rat brain. J Neurosci 7:565-570.

Seutin V, Johnson SW, North RA. 1993. Apamin increases NMDA-induced burst-firing of rat mesencephalic dopamine neurons. Brain Res 630 341-344.

Simard M Nedergaard M. 2004. The neurobiology of glia in the context of water and ion homeostasis. Neuroscience 129:877-896.

Sladek CD. Antidiuretic hormone: synthesis and release. 2000. In: Fray JCS, editor. Handbook of Physiology, Section 7, The Endocrine System, Volume III. Endocrine Regulation of Water Balance and Electrolyte Balance. Oxford: Oxford University Press, p 436-495.

Sontheimer H. 1994. Voltage-dependent ion channels in glial cells. Glia 11:156-172.

Stern JE, Galarreta M, Foehring RC, Hestrin S, Armstrong WE. 1999 Differences in the properties of ionotropic glutamate synaptic currents in oxytocin and vasopressin neuroendocrine neurons. J Neurosci 19 3367-3375.

Stocker M, Pedarzani P. 2000. Differential Distribution of Three $\mathrm{Ca}(2+)$ Activated $\mathrm{K}(+)$ Channel Subunits, SK1, SK2, and SK3, in the Adult Rat Central Nervous System. Mol Cell Neurosci 15:476-493.

Tacconi S, Carletti R, Bunnemann B, Plumpton C, Merlo Pich E, Terstappen GC. 2001. Distribution of the messenger RNA for the small conductance calcium-activated potassium channel SK3 in the adult rat brain and correlation with immunoreactivity. Neuroscience 102:209215.

Taylor MS, Bonev AD, Gross TP, Eckman DM, Brayden JE, Bond CT, Adelman JP, Nelson MT. 2003. Altered expression of smallconductance $\mathrm{Ca}^{2+}$-activated $\mathrm{K}^{+}$(SK3) channels modulates arterial tone and blood pressure. Circ Res 93:124-131.

Teruyama R, Armstrong WE. 2002. Changes in the active membrane properties of rat supraoptic neurones during pregnancy and lactation. J Neuroendocrinol 14:933-944.

Theodosis DT, Piet R, Poulain DA, Oliet SH. 2004. Neuronal, glial and synaptic remodeling in the adult hypothalamus: functional consequences and role of cell surface and extracellular matrix adhesion molecules. Neurochem Int 45:491-501.

Verbalis JG, Mangione MP, Stricker EM. 1991. Oxytocin produces natriuresis in rats at physiological plasma concentrations. Endocrinology 128:1317-1322

Villalobos C, Shakkottai VG, Chandy KG, Michelhaugh SK, Andrade R. 2004. SKCa channels mediate the medium but not the slow calciumactivated afterhyperpolarization in cortical neurons. J Neurosci 24 3537-3542.

Wolfart J, Neuhoff H, Franz O, Roeper J. 2001. Differential expression of the small-conductance, calcium-activated potassium channel SK3 is critical for pacemaker control in dopaminergic midbrain neurons. J Neurosci 21:3443-3456.

Yamazaki RS, Chen Q, Schreiber SS, Brinton RD. 1997. Localization of V1a vasopressin receptor mRNA expression in cultured neurons, astroglia, and oligodendroglia of rat cerebral cortex. Brain Res Mol Brain Res 45:138-140.

Zhao L, Brinton RD. 2002. Vasopressin-induced cytoplasmic and nuclear calcium signaling in cultured cortical astrocytes. Brain Res 943:117131. 